\title{
Correction to: A Limiting Channel Capacity of Visual Perception: Spreading Attention Divides the Rates of Perceptual Processes
}

Joseph S. Lappin ${ }^{1,2} \cdot$ Adriane E. Seiffert $^{1} \cdot$ Herbert H. Bell ${ }^{2}$

Published online: 26 July 2020

(C) The Psychonomic Society, Inc. 2020

Correction to: Attention, Perception, \& Psychophysics, 82, 2652-2672 https://doi.org/10.3758/s13414-020-01973-9

An error occurred in labeling the data in Fig. 5a-b, p. 2661. The figure caption is correct as printed. A corrected Fig. 5 is below.

The online version of the original article can be found at https://doi.org/ 10.3758/s13414-020-01973-9

Joseph S. Lappin

joe.lappin@Vanderbilt.Edu

1 Vanderbilt University, Nashville, TN, USA

2 Discerning Technologies LLC, San Diego, CA, USA 
a
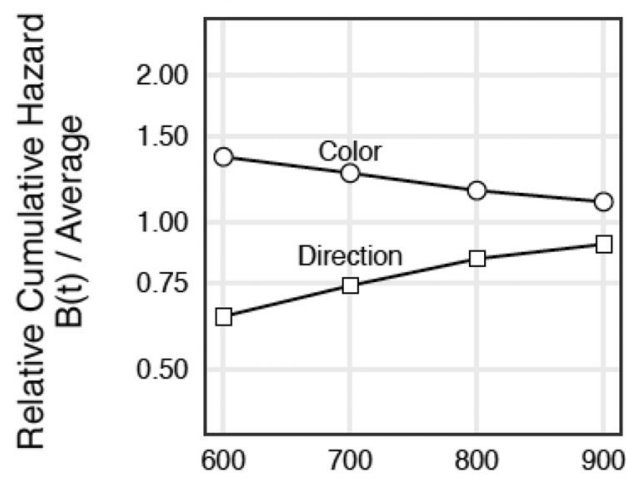

Response Time (ms)

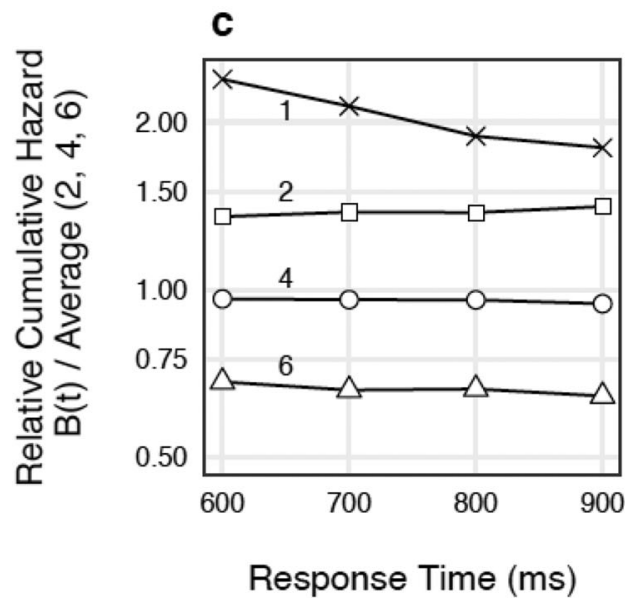

b

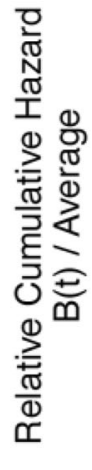

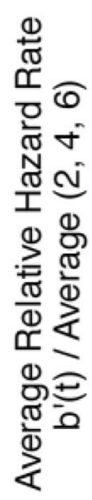

0.50

$600-700 \quad 700-800 \quad 800-900$

Response Time (ms)

Publisher's note Springer Nature remains neutral with regard to jurisdictional claims in published maps and institutional affiliations. 